\title{
FULL-SCALE REINFORCED CONCRETE SLABS: BLAST EFFECTS, DAMAGE CHARACTERIZATION AND NUMERICAL MODELLING
}

\author{
RICARDO CASTEDO*, LINA MA LOPEZ ${ }^{\dagger}$, MARIA CHIQUITO $\&$ ANASTASIO P. SANTOS ${ }^{\ddagger}$ \\ Dpto. de Ingeniería Geológica y Minera, E.T.S.I. Minas y Energía, Universidad Politécnica de Madrid.
}

\begin{abstract}
This work investigates the response of a blast loaded reinforced slab with different constructive characteristics. This topic has been well covered during the last years, but there are a reduce number of them that presents blast test at realistic scale. Seven different slabs were tested: three at a scaled distance of $0.79 \mathrm{~m} / \mathrm{kg}^{1 / 3}$, one at $0.41 \mathrm{~m} / \mathrm{kg}^{1 / 3}$ and four with $0.20 \mathrm{~m} / \mathrm{kg}^{1 / 3}$. The three tests with high-scaled distance, used as calibration tests, have been characterized with pressure gauges and accelerometers. These reinforced slabs are the same as the one of low-scaled distance and one of high-scaled distance. Finally, the two tests of low-scaled distance have different reinforcement: steel or polypropylene fibres. The blast effects over the slabs has been characterized with a non-destructive methodology based on the Schmidt hammer. The methodology consists on the evaluation of a statistically significant difference of six rebound values before and six after a blast event for each evaluation point, having 19 evaluation point for each slab face. Based on each individual damage value, damage maps have been created using an interpolation tool. This methodology is very useful to quantify the non-visual damage of a structural element and to validate numerical modelling results. In this case, a 3D Lagrangian simulation using the LS-DYNA code with the blast load routine called CONWEP was done. The results in the developed model are affected by the scaled distance and by the construction patterns. The blast resistance of the slabs were better when using steel or polypropylene fibres, especially under tensile stresses (bottom part of the slabs).

Keywords: explosives, full-scale slabs, LS-DYNA, non-destructive testing, reinforced concrete, Schmidt hammer.
\end{abstract}

\section{INTRODUCTION}

Reinforced concrete is a well-known building materials basically employed in the construction of train or bus stations, airports, roads, dumps and houses. The concrete has very good characteristics such as low price, high fire resistance, manufacturing and relatively good mechanical characteristics. But in the last years many threats arose, using improvised explosive devices - IEDs (Boston, 2013; Paris, 2015; Brussels, 2016), that put these facilities into high risk. Therefore, it is critical to investigate and quantify the response of building materials strength after a blast loading.

The number of casualties can be of great importance if the affected structure is collapsed. Two main techniques has been used to improve the materials' resistance i.e. internal or external reinforcement. As an internal reinforcement it is common to use fibres such as steel [1,2], carbon $[3,4]$ or polypropylene $[5,6]$; while for the external elements it is common to use aluminium foam [7] or steel sheets [8]. Nowadays, the use of modelling tools has been extended worldwide as they are relatively cheap and the field validation is expensive;

\footnotetext{
* http://orcid.org/0000-0002-5725-6272

$\dagger$ http://orcid.org/0000-0001-6250-0893

$\ddagger$ http://orcid.org/0000-0003-2207-6674

$\S$ http://orcid.org/0000-0003-2708-9378
} 
however, they should be corroborated with experimental data [9]. There are some commercial options for modelling structural nonlinear dynamic responses i.e. AUTODYN [10] and LS-DYNA [11]. Even though, the numerical modelling has a significant improvement in the last years, more numerical studies with field validation are necessary to understand the complexity of dynamic response [12].

There are several non-destructive methods (NDTs) to measure the materials properties without affecting the structural integrity of it. While all the available methodologies had some limitations, the rebound hammer provides quick, inexpensive means of checking the uniformity of concrete. However, the measurements made with this technology can be affected by the age of specimens, smoothness of test surface, moisture conditions of the concrete and type of cement and coarse aggregate [13].

In this paper, a 3D Lagrangian model with the combination of CONWEP, is developed in LS-DYNA. The model simulate the structural behaviour of reinforced concrete slabs at real (full) scale under an explosive shock wave. The modelling results are validated with experimental data (pressure and acceleration signals), with the evaluation of the surface damage on each face (simulation versus tests) and with a non-destructive methodology based on the Schmidt hammer rebound value.

\section{TEST DESCRIPTION}

Seven reinforced concrete slabs were done at realistic scale using diverse arrangements of explosive mass and distance, at the Technological Institute of "La Marañosa" (Spain) from 2010-2014.

Five slabs were built only with reinforced concrete, they are known as S1 to S5. Another two slabs were manufactured with the addition of steel fibres (slab S6) and polypropylene fibres in S7. The slabs measurement and thickness as long as the test setp-up can be shown in Fig. 1. The steel reinforce was done with a $12 \mathrm{~mm}$ diameter rebar spaced $150 \mathrm{~mm}$ in both dimensions with a concrete cover of about $30 \mathrm{~mm}$ on both faces. The Table 1 shows the materials properties, taking into account that nominal values are given for the concrete and steel bars.

The plastic explosive used called PG2 (similar to the well-known C4), a RDX-based (86\%), had a TNT equivalent of 0.86 based on impulse [14]. Two equivalent masses ( $W$ equal to 2 and $15 \mathrm{~kg}$ ) were used. The charges were placed at the slab centre at two distances $(R)$ equal to 1 and $0.5 \mathrm{~m}$. The combination of $W$ and $R$ allowed to probe three scaled distances $Z$ $=R / W^{1 / 3}$ ) ranging from 0.79 to $0.2 \mathrm{~m} / \mathrm{kg}^{1 / 3}$. The explosive in slabs $\mathrm{S} 1-\mathrm{S} 3$ was located at $Z$ equal to $0.79 \mathrm{~m} / \mathrm{kg}^{1 / 3}$, in $\mathrm{S} 4$ at $0.41 \mathrm{~m} / \mathrm{kg}^{1 / 3}$ and in $\mathrm{S} 5$ at $0.20 \mathrm{~m} / \mathrm{kg}^{1 / 3}$. While the explosive in slabs S6 and S7 was located at a scaled distance equal to $0.20 \mathrm{~m} / \mathrm{kg}^{1 / 3}$.

\subsection{Measuring devices}

The measuring devices were only used at the high scaled distance tests (S1-S3), as the risk of damage them in the big charge tests were very high, so these tests were used to calibrate the material used in the modelling. As can be seen in Fig. 1, three accelerometers were used (although the data from two of them should be the "same") and two pressure transducers with ablative protection. The measuring range of the pressure transducer called P1 (Fig. 1) was $\pm 34.475 \mathrm{MPa}$ while the range for the $\mathrm{P} 2$ was $\pm 3.450 \mathrm{MPa}$, the resolutions were $1.38 \times 10^{-4}$ $\mathrm{MPa}$ and $1.4 \times 10^{-5} \mathrm{MPa}$, respectively. The measuring range for the A1 accelerometer was $\pm 10,000 \mathrm{~g}(0.2 \mathrm{~g}$ of resolution) and the measuring range for the $\mathrm{A} 2$ and $\mathrm{A} 3$ was $\pm 5,000 \mathrm{~g}(0.02$ $\mathrm{g}$ of resolution). The acquisition system used to register all these data was a Nicolet Genesis 


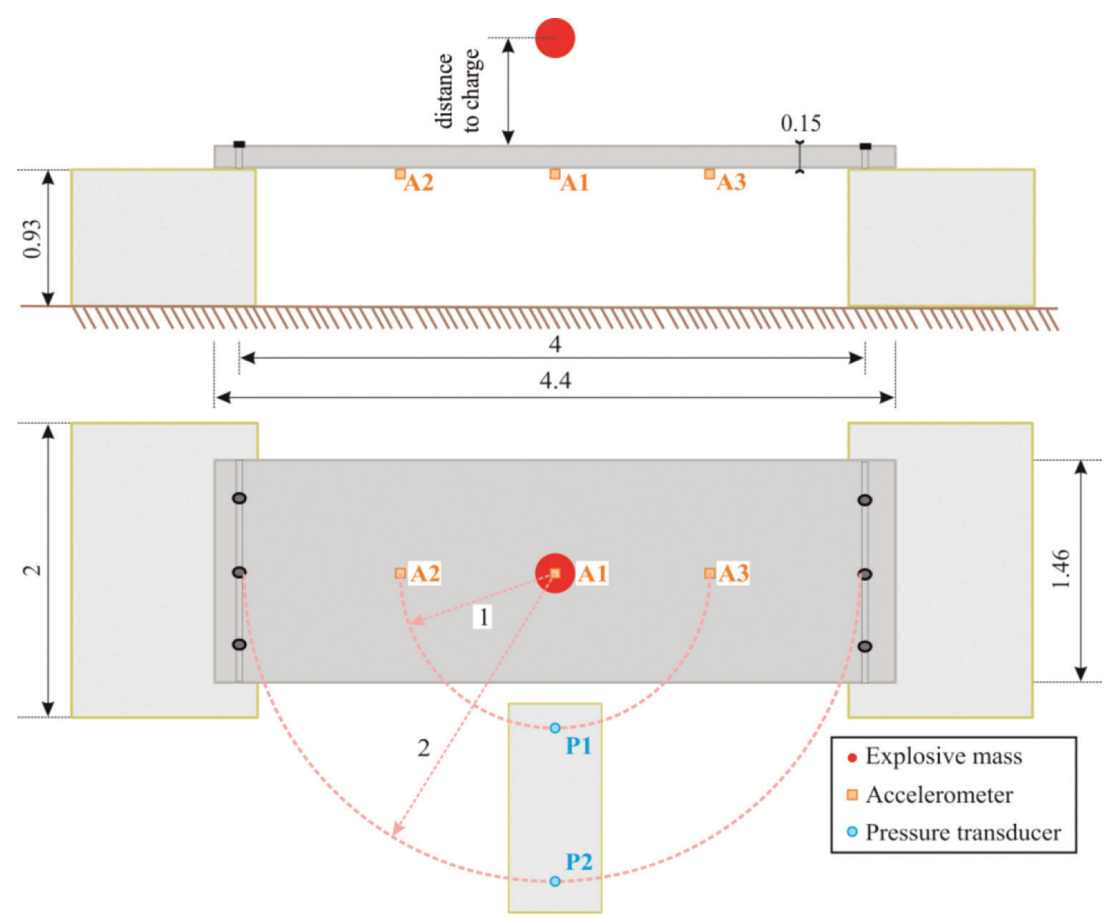

Figure 1: General test set-up. Location of the accelerometers and pressure transducers in tests S1-S3. Note that these measurement devices were removed for safety reasons for the other tests.

Table 1: Materials' characteristics. Being SF steel fibres and PPF polypropylene fibres added to the $\mathrm{RC}$ reinforced concrete.

\begin{tabular}{lllll}
\hline Property & Concrete & Steel bar & SF+RC & PPF+RC \\
\hline Density $\left(\mathrm{kg} / \mathrm{m}^{3}\right)$ & 2300 & 7850 & $120^{(1)}$ & $9^{(1)}$ \\
Length $(\mathrm{mm})$ & - & - & $50^{(1)}$ & $48^{(1)}$ \\
Diameter $(\mathrm{mm})$ & - & - & $1^{(1)}$ & $0.84^{(1)}$ \\
Volume fraction $(\%)$ & - & - & 1.5 & 1 \\
Concrete compressive strength, $f_{c}(\mathrm{MPa})$ & 25 & - & 44.16 & 43.33 \\
Tensile Strength $(\mathrm{MPa})$ & 3.7 & 550 & 8.12 & 5.62 \\
Young Modulus $(\mathrm{MPa})$ & $273 \times 102$ & $200 \times 103$ & - & - \\
Yield strength $(\mathrm{MPa})$ & - & 500 & - & - \\
\hline
\end{tabular}

(1) Fibre properties.

multichannel with different velocity of registration for pressure $(500 \mathrm{kHz})$ and acceleration $(50 \mathrm{kHz})$.

\section{DAMAGE ASSESMENT}

The physical measurement of damage for concrete specimens has been evaluated with the Schmidt hammer in combination with the relative area of damage. 


\subsection{Surface damage}

The surface damage $\left(d_{A}\right)$ can be defined, for field specimens, as the ratio of spalled area to initial surface area. For the numerical modelling it is the ratio of eroded (spalling) elements to the total elements on the initial surface $\left(d_{M}\right)$.

\subsection{Rebound hammer damage assessment}

Only a brief description of the methodology will be done here as it can be found in detail in Lopez et al. [15]. The Schmidt hammer used was type $\mathrm{N}$ with an impact energy of $2.207 \mathrm{Nm}$ calibrated for a concrete compressive strength range from 10 to $100 \mathrm{~N} / \mathrm{mm}^{2}$. One measurement location point (with a circular area of $4 \mathrm{~cm}$ radius) was defined with twelve points around the coordinates: six for the evaluation before and six for the evaluation after the explosion (Fig. 2). Both medians are compared, using the Wilcoxon rank-sum test, if a p-value less than 0.05 is obtained, it can be stated that the rebound number decreases after the explosion with a 95\% confidence level. Damage value ranks from 0 up to 1 for a "non-damage" and "total-damage" point, respectively. When p-value is lower than 0.05 , the damage $\left(d_{H}\right)$ is defined as following:

$$
d_{H}=1-\frac{\text { measurements after }}{\text { measurements before }}
$$

while p-value is higher than 0.05 the damage is defined as $d_{H}=0$. For the slab evaluation, 19 points were made to the top face as in most cases the bottom face where not accessible to make the measures. In addition, and to complete the analysis, a damage or contour map based on these results is generated in Matlab with the instruction called "griddata". To avoid the overestimation of the mean damage value due to heterogeneous density of evaluation points, the global considered damage, called $d_{200}$, can be defined as the mean of the interpolated values of these 200 points. This parameter has been calculated only for the top face (the face against the explosive).

\section{NUMERICAL MODELLING}

The use of 3D full-scale finite element modelling is fundamental to understand, predict and simulate the failure mechanism and the damage area of concrete structures against blasting. The numerical models were done using the finite element software LS-DYNA Version 971R4. It is based numerical methods that are appropriate for problems solution related with great deformation due to high impact event such an air blast. As has been mentioned, realistic
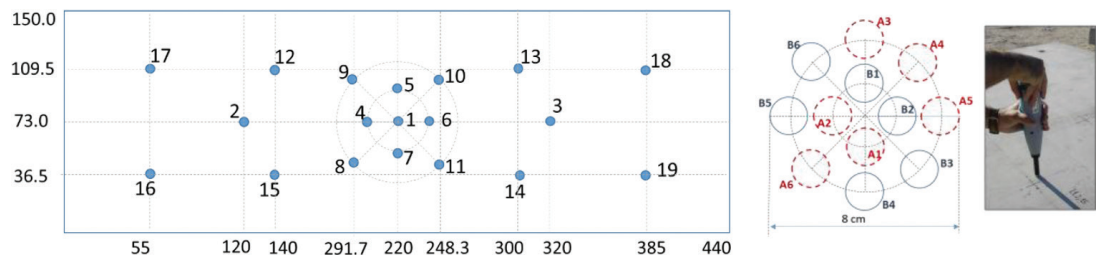

Figure 2: Points locations for slabs (units in $\mathrm{cm}$ ). Definition of one evaluation point. $B_{i}$ and $A_{i}$ are the positions before and after test, respectively. The diameter of each measurement point is $1.5 \mathrm{~cm}$. 
(full) scale slabs were modelled in 3D and solved using lagrangian mesh. To save computational time, and taking advantage of the symmetry conditions, only one half along the major axis of each slab is considered.

The concrete was discretized using 3D solid elements and beams elements were used to reproduce the steel reinforcement. Assuming a perfect link between both elements, the rebar contacted the concrete with the command *Constrained_Lagrange_in_Solid. This assumption suppose that there is no sliding between elements as the event time is really short and the pressures are really high. Based on the convergence theorem, to find an accurate solution with the lowest computational time, the mesh size should be as fine as necessary and as coarse as possible. The concrete area in which the cracks are produced, namely concrete fracture progress zone (CFPZ), can be assumed to happen in just one mesh element for the numerical model. The fracture energy can be totally lost, if the selected mesh size is higher than the CFPZ; on the contrary, if the selected mesh size is smaller the CFPZ can cover more than one element producing higher damage. Based on this idea, and taking into account numerical and physical restrictions, a detailed analysis can be found in [16] showing that the ideal concrete size is $15 \times 15 \times 15 \mathrm{~mm}$ and $50 \mathrm{~mm}$ bars for the steel. The number of solid elements used to define the concrete are 142,440, while the beam elements (steel reinforcement) are 1,758.

The explosive charge has been introduced into the model with the function called *Load Blast_Enhanced (LBE). This function is based on the Kingery-Bulmash empirical blast data [11].

A plasticity-based model, known as CSCM [3], was used to simulate the concrete material in the slabs. The CSCM model has a great advantage, for its use only one parameter is mandatory: the unconfined compressive strength $f_{c}$ (Table 1). The other parameters are created by a built-in algorithm but can be modified by the user. The generated parameters described the fracture energy for several cases such as tension, shear and compression. The material erosion is computed when the elements reach a $99 \%$ of its internal damage [17], and can be checked by plotting the plastic strain in the LS-PrePost. The damage parameter goes from 0 to 1 for no damage to fully damage, respectively. When using the non-fibre concrete, material dataset was generated by the LS-DYNA algorithm starting from the concrete nominal value of $15 \mathrm{MPa}$. However, and following different authors [2, 5-6], starting from the automatic parameters any modification can be done to reproduce a particular concrete. In this case, the fracture energy parameter $\left(G_{f}\right)$ in tension was modified to $6.835 \mathrm{MPa}-\mathrm{mm}$ for the steel fibres and 4.1 MPa-mm for the polypropylene ones. These values are extracted from published sources [18-19] and from the Structural Concrete National standard [20] (see Castedo et al. [21] for more details). The fibre orientation were unknown and also impossible to be reproduced by the model.

The piecewise linear plasticity material model was used to reproduce the reinforcement steel bars behaviour. This material model deals with the stress strain by a bilinear curve considering strain rate effects. According to the European standard the steel used was B-500 S [22].

\section{RESULTS AND DISCUSSION}

The results are analysed from the biggest scaled distance to the lowest one.

\subsection{Calibration tests (low mass explosive tests)}

Damage calculated with the Schmidt hammer $\left(d_{200}\right)$, surface damage in the field $\left(d_{A}\right)$ and numerical modelling damage $\left(d_{M}\right)$ is zero for the tests S1-S3. Only a few cracks appears at the bottom face of the slab (the opposite face to the explosive). The model is able to 
reproduce them well but for conciseness they are not showed here (see Castedo et al. [21] for more details).

The peak reflected pressures ranged were from 3.30 to $3.61 \mathrm{MPa}$ and from 0.49 to 0.58 $\mathrm{MPa}$ at locations P1 and P2, respectively (Fig. 1). The numerical value for the P1 point was 3.45 MPa while the value for the $\mathrm{P} 2$ point was $0.49 \mathrm{MPa}$. Both results were inside the measuring range, showing that the numerical model in terms of pressure is well applied. The peak particle acceleration went from 7.61 to $9.76\left(\times 10^{3}\right) g$ at point A1 and from 1.70 to 2.29 $\left(\times 10^{3}\right) g$ at points A2-3. The numerical values obtained were 9.56 and 1.73 for points A1 and A2-3, respectively. This also shows that the numerical model developed here is able to capture the acceleration peak applied due to the blasting.

\subsection{Effect of the scaled distance}

The slab S4 presented a different failure pattern as it was bent over its minor side. The spalling appeared on both surfaces (Fig. 3), even with no evident hole on any face. In this case, the surface damage has been calculated as the spalling area. Contrasting with previous slabs, several cracks were generated after detonation at the top of the slab. The damage map shows a good agreement between the numerical modelling and the real test results. Data from the damage numbers can be seen in Table 2 . The $d_{200}$ parameter is higher than the others, while the numerical modelling at the top surface is the worst from the full slabs set.

With the scaled distance of $0.20 \mathrm{~m} / \mathrm{kg}^{1 / 3}$ the slab S5 can be used as the contract data to compare the fibre behaviour (Fig. 4). The $d_{A}$ value was $6.9 \%$ and $27.4 \%$ for the top and bottom surface, respectively. On the top, the damage value is really high when comparing with $\mathrm{S} 4$. On the bottom, where the concrete works in tension, the damage in really noticeable. Both damages are reproduced by the numerical modelling with a low error of less than $10 \%$.
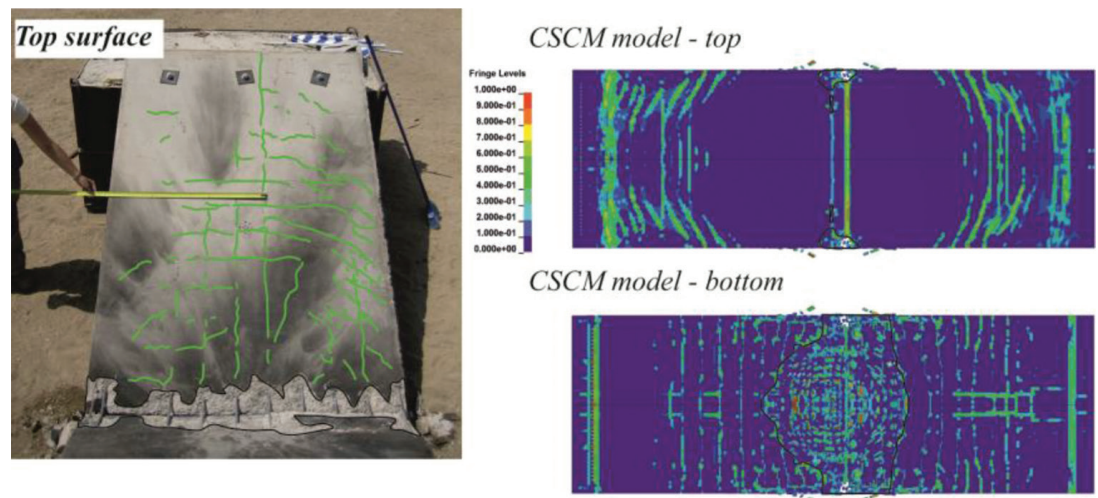

Contour damage map - top

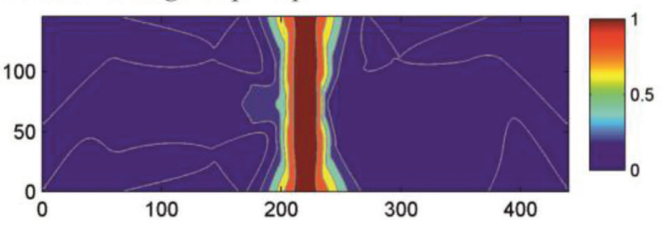

Figure 3: Testing of slab S4. The numerical modelling scale shows plastic strain. At the bottom, the hammer rebound damage map is shown with his damage scale. 
Table 2: Damage parameters for slabs. Values in percentage.

\begin{tabular}{|c|c|c|c|c|c|c|c|}
\hline \multirow[b]{2}{*}{ Test \# } & \multirow{2}{*}{$\begin{array}{l}\text { Scaled } \\
\text { distance } \\
\mathrm{m} / \mathrm{kg}^{1 / 3}\end{array}$} & \multirow[b]{2}{*}{ Damage } & \multirow{2}{*}{$\begin{array}{l}\text { Damage } \\
d_{200}\end{array}$} & \multicolumn{2}{|c|}{$\begin{array}{l}\text { Area damaged in } \\
\text { tests }\end{array}$} & \multicolumn{2}{|c|}{$\begin{array}{l}\text { Area damaged in } \\
\text { numerical models }\end{array}$} \\
\hline & & & & $d_{A, \text { top }}$ & $d_{A}$, bottom & $d_{M, \text { top }}$ & $d_{M}$, bottom \\
\hline $\mathrm{S} 1, \mathrm{~S} 2, \mathrm{~S} 3$ & 0.79 & No damage & - & - & - & - & - \\
\hline $\mathrm{S} 4$ & 0.40 & Moderate & 10 & 3.4 & - & 2.1 & 17.3 \\
\hline S5 & 0.20 & Severe & 27 & 6.9 & 27.4 & 6.5 & 24.8 \\
\hline S6 & 0.20 & Severe & 27 & 5 & 13.1 & 5.6 & 14.7 \\
\hline S7 & 0.20 & Severe & 28 & 6.1 & 14.9 & 6.5 & 17.2 \\
\hline
\end{tabular}

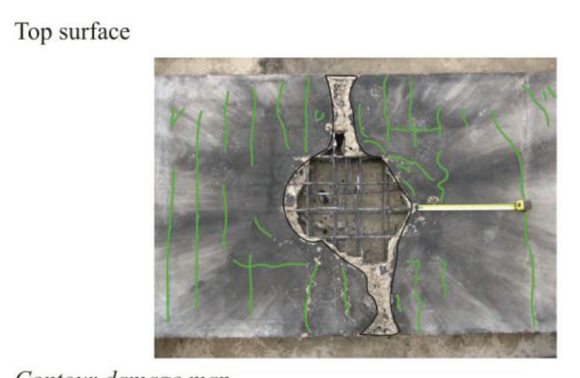

Bottom surface
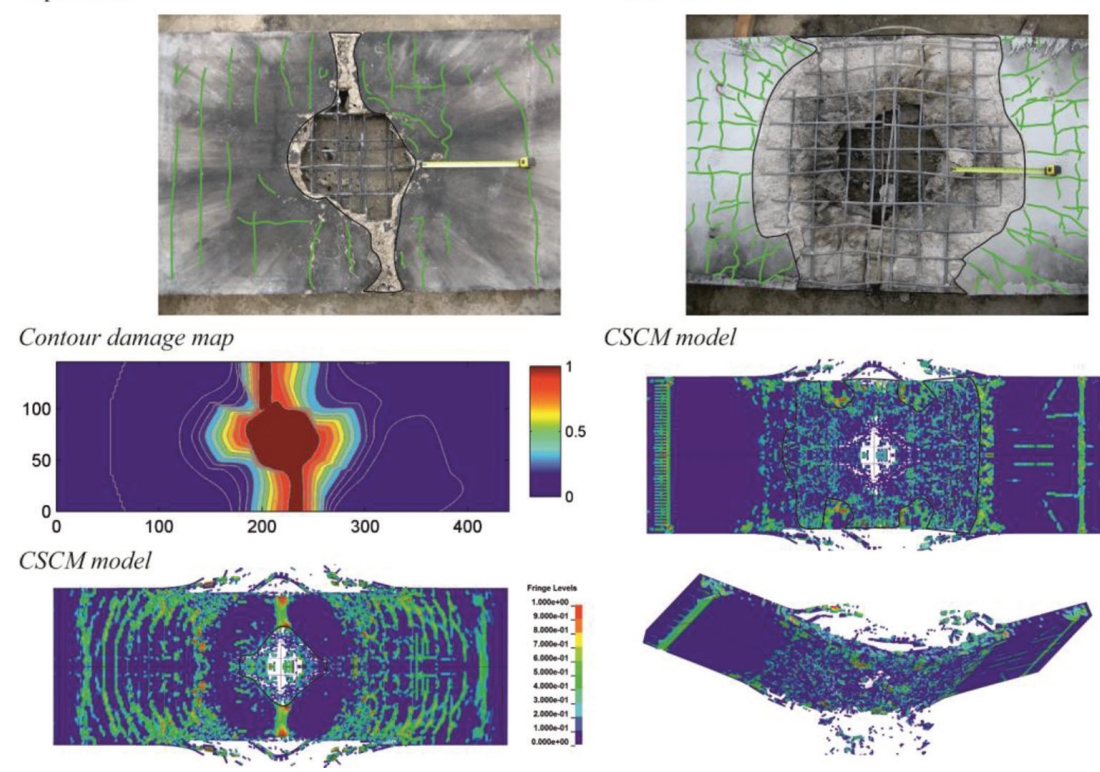

CSCM model

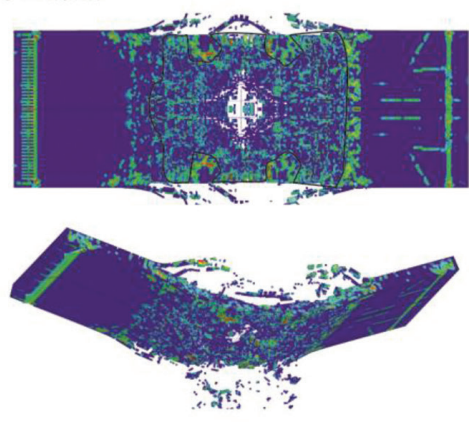

Figure 4: Testing slab S5. The contour damage is shown with his damage scale. The numerical modelling scale shows plastic strain.

As happened with the slab S4 the contour damage map reproduce fairly well the spalling found in the tests, however the $d_{200}$ value is again higher than the other estimators are.

\subsection{Effect of the fibre reinforcement}

Slabs S6 and S7 were tested with the same scaled distance $(Z)$ of the slab S5. Details of their results can be seen in Figs 5 and 6. Both had an axial failure with a round hole at its centre, but both have lower damage values than S5. However, the results are quite similar on the top face, where the concrete works under compression. On the contrary, the addition of fibres enhanced the results on the bottom face where the concrete works under tensile stresses highlighting that the fibres significantly improve the tensile strength of the slab. The experimental 

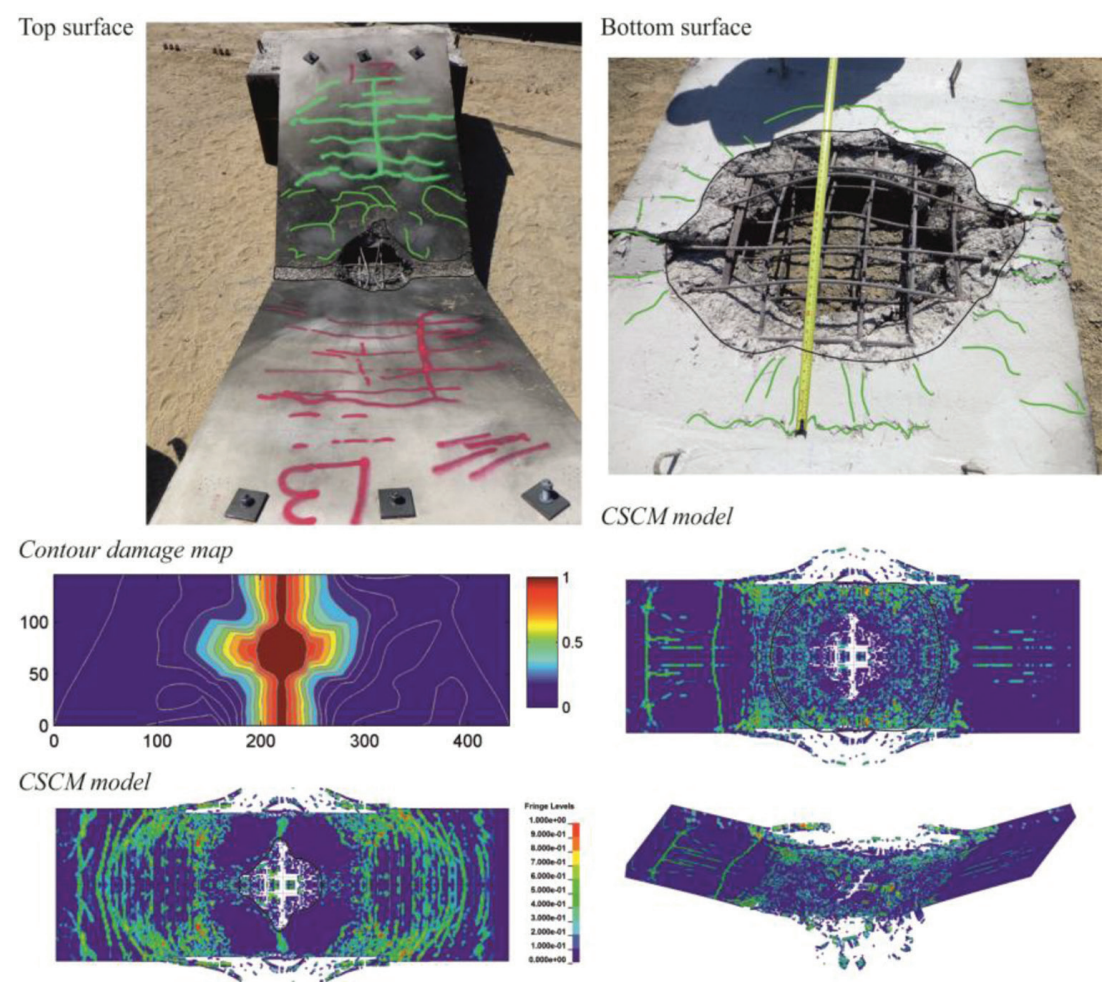

CSCM model
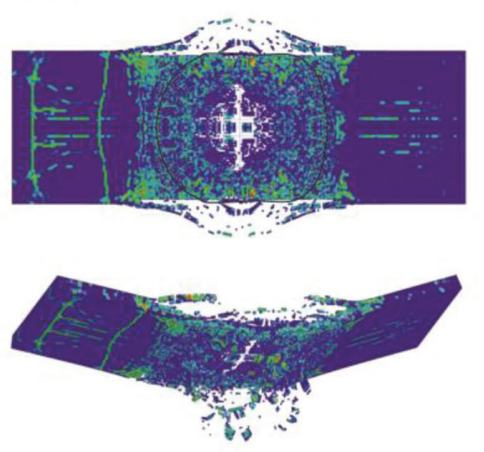

Figure 5: Results from testing slab S6. The contour damage is shown with his damage scale. The numerical modelling scale shows plastic strain.

damage is slightly smaller in slab S6, in which steel fibres were used, in comparison with slabs at the same scaled distance (S5, and S7). Results from numerical simulation are consistent with those observed in the field; as a matter of example, numerical model for slab S7 had high plastic strain deformation following the length of its vertical axis, which is in accordance with surface damage of the test (Fig. 6). The numerical surface damage for slabs S6 and $\mathrm{S} 7$ is also smaller than that in S5, with a relative error ranged from 7 to $15 \%$, with S6 as the slab with minor damage. Again when comparing the results of the contour damage map, they are able to reproduce the damage pattern found in the tests and the pattern found in the numerical models.

It can be seen that the steel reinforcement determines in some way the overall crack pattern, and the numerical model is able to reproduce this feature. Also, the model is sensible to changes in explosive charge or distance that is why it can be used with confidence in future simulations.

\section{CONCLUSIONS}

Several slabs has been tested against explosive charges to investigate its resistance, to calibrate and validate numerical models and to use a developed non-destructive technique to evaluate the superficial damage.

It is well-known that the close-in blast are difficult to modelize, however as it has been demonstrated here a full-scale 3D model can be used with confidence. The model includes 


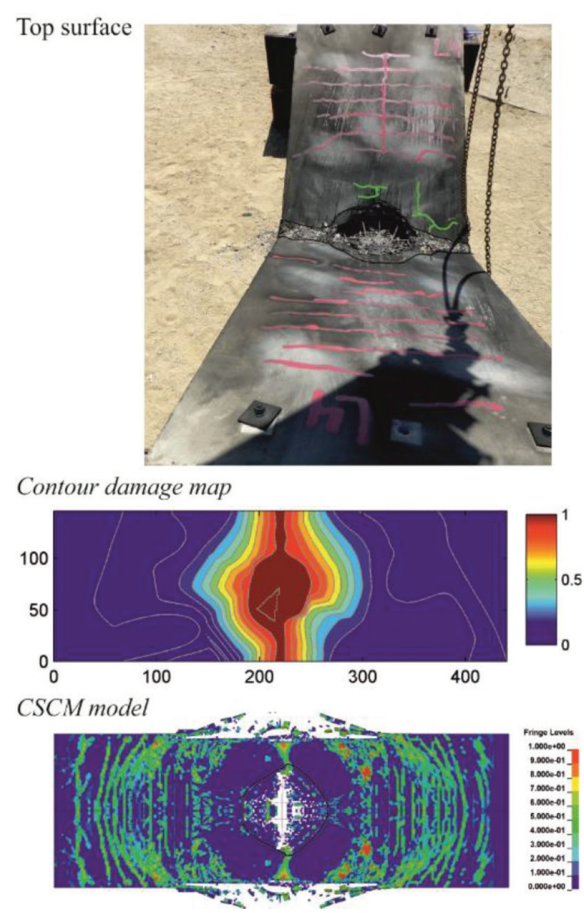

Bottom surface

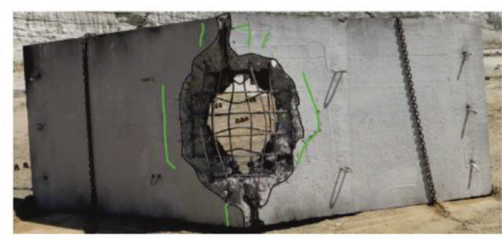

CSCM model
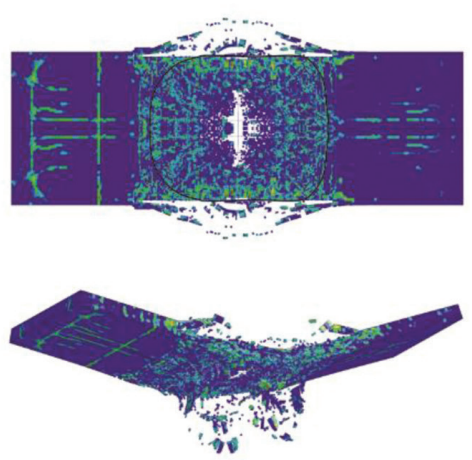

Figure 6: Testing slab S7. The contour damage is shown with his damage scale. The numerical modelling scale shows plastic strain.

the use of CSCM material with some minor modifications (to replicate the addition of fibres) and the CONWEP module to reproduce the explosive charge. The mean damage error of the numerical simulation is $13.81 \%$ being a good value for engineering purposes.

The combination of the global damage value $\left(d_{200}\right)$ and the damage maps, show that the rebound hammer can be used to quantify blasting effects over different constructive solutions. This feature is especially important when the structural damage is not critical and the human eye cannot evaluate the damage with a mere visual inspection. In addition, the global damage value responses well to differences in scaled distance as happens in real tests, so it can be used with confidence to quantify post-blasting effects at different situations

A future work (and actually present work) is to explicitly correlate the damage values obtained in the contour damage maps with the numerical simulations to get a double check to validate the models, especially when the damage is not full (only superficial damage) that otherwise is impossible to validate.

\section{ACKNOWLEDGEMENTS}

This work has been done under the SEGTRANS project, funded by the Centre for Industrial Technological Development (CDTI, Government of Spain). We would like to thank all the people from TAPUSA, EUROESTUDIOS, KV Consultores and Sacyr who contributed to the design and execution of the tests. We also thank the staff in La Marañosa (ITM-INTA) for their help at the testing site. 


\section{REFERENCES}

[1] Silva, P.F. \& Lu, B., Improving the blast resistance capacity of RC slabs with innovative composite materials. Composites Part B-Engineering, 38(5), pp. 523-534, 2007. https://doi.org/10.1016/j.compositesb.2006.06.015

[2] Mao, L., Barnett, S., Begg, D., Schleyer, G. \& Wight, G., Numerical simulation of ultra-high performance fibre reinforced concrete panel subjected to blast loading. International Journal of Impact Engineering, 64, pp. 91-100, 2014.

https://doi.org/10.1016/j.ijimpeng.2013.10.003

[3] Tabatabaei, Z.S, Volz, J.S, Baird, J., Gliha, B.P. \& Keener, D.I., Experimental and numerical analyses of long carbon fiber reinforced concrete panels exposed to blast loading. International Journal of Impact Engineering, 57, pp. 70-80, 2013. https://doi.org/10.1016/j.ijimpeng.2013.01.006

[4] Pantelides, C.P., Garfield, T.T., Richins, W.D., Larson, T.K. \& Blakeley, J.E., Reinforced concrete and fiber reinforced concrete panels subjected to blast detonations and post-blast static tests. Engineering Structures, 7, pp. 24-33, 2014. https://doi.org/10.1016/j.engstruct.2014.06.040

[5] Foglar, M. \& Kovar, M., Conclusions from experimental testing of blast resistance of FRC and RC bridge decks. International Journal of Impact Engineering, 59, pp. 18-28, 2013. https://doi.org/10.1016/j.ijimpeng.2013.03.008

[6] Kovar, M. \& Foglar, M., An analytical description of the force-deflection diagram of FRC. Composites Part B-Engineering, 69, pp. 550-561, 2015. https://doi.org/10.1016/j.compositesb.2014.10.021

[7] Wu, C. \& Sheikh, H., A finite element modelling to investigate the mitigation of blast effects on reinforced concrete panel using foam cladding. International Journal of Impact Engineering, 55, pp. 24-33, 2013. https://doi.org/10.1016/j.ijimpeng.2012.11.006

[8] Ghani Razaqpur, A., Tolba, A. \& Contestabile, E., Blast loading response of reinforced concrete panels reinforced with externally bonded GFRP laminates. Composites Part B-Engineering, 38(5), pp. 535-546, 2007. https://doi.org/10.1016/j.compositesb.2006.06.016

[9] Spranghers, K., Vasilakos, I., Lecompte, D., Sol, H. \& Vantomme, J., Numerical simulation and experimental validation of the dynamic response of aluminum plates under free air explosions. International Journal of Impact Engineering, 54, pp. 83-95, 2013. https://doi.org/10.1016/j.ijimpeng.2012.10.014

[10] AUTODYN, v4.2 user manual. Century Dynamics, Inc.; 2001.

[11] LSTC. LS-DYNA Version 971 Keyword User's Manual_Rev5-beta, Livermore Software Technology Corporation; 2010.

[12] Lin, X., Zhang, Y.X. \& Hazell, P.J., Modelling the response of reinforced concrete panels under blast loading. Materials Design, 56, pp. 620-628, 2014. https://doi.org/10.1016/j.matdes.2013.11.069

[13] Malhotra, V.M. \& Carino, N.J., (eds.), Handbook on Nondestructive Testing of Concrete. Second Edition. CRC press: Boca Raton, 2003.

[14] López, L.M., Sanchidrián, J.A., Piedra, L.J. \& Ríos, J., Shock wave pressure in underground explosions. , Procedings of 2 nd World Conference on Explosives and Blasting Technique-Prague, ed. R. Holmberg, Lisse-The Netherlands: Taylor \& Francis, pp. 335-343, 2003. 
[15] López, L.M., Castedo, R., Segarra, P., Sanchidrián, J.A., Santos, A.P., Navarro, M. \& Chiquito, M., Post-blast non-destructive damage assessment on full-scale structural elements. Journal of Non-Destructive Evaluation. Under review.

[16] Alañón, A., Cerro-Prada, E., Vázquez-Gallo, M.J. \& Santos, A.P., Mesh size effect on finite-element modeling of blast-loaded reinforced concrete slab. Engineering with Computers, 34(4), pp. 649-658, 2018.

[17] Magallanes, J.M. Importance of concrete material characterization and modelling to predicting the response of structures to shock and impact loading. Structures under shock and impact $X$, eds. N. Jones, C.A. Brebbia . Algarve (Portugal): WIT Press, pp. 241-250, 2008.

[18] Holmquist, T.J., Johnson, G.R. \& Cook, W.H., A computational constitutive model for concrete subjected to large strains, high strain rate, and high pressures. In: 14th International Symposium on Ballistics, Canada, 1993.

[19] Cronin, D.S., Bui, K., Kaufmann, C., McIntosh, G. \& Berstad, T., Implementation and validation of the Johnson-Holmquist ceramic material model in LS-DYNA. In 4th European LS-DYNA Users Conference, Germany, 2003.

[20] Spain. Real Decreto 1247/2008, de 18 de julio, por el que se aprueba la instrucción de Hormigón Estructural (EHE-08). Boletín Oficial del Estado, 2008 August 22, 203, pp. 35176-35178, 2008.

[21] Castedo, R., Segarra, P., Alañon, A., Lopez, L.M., Santos, A.P. \& Sanchidrian, J.A., Air blast resistance of full-scale slabs with different compositions: numerical modeling and field validation. International Journal of Impact Engineering, 86, pp. 145-156, 2015. https://doi.org/10.1016/j.ijimpeng.2015.08.004

[22] Spain. Real Decreto 751/2011, de 27 de mayo, por el que se aprueba la instrucción de Acero Estructural (EAE). Boletín Oficial del Estado, 2011 June 23, 149, pp. 6714867151, 2011. 